July 2021

\title{
Importance-implementation of disability management practices in hotels: The moderating effect of team orientation
}

Zakaria Elkhwesky

Alexandria University, Egypt, zakaria.elkhwesky@alexu.edu.eg

Islam Elbayoumi Salem

Alexandria University, Egypt, islam.sal@cas.edu.om

Mona Barakat

Alexandria University, Egypt, mona_barakat2000@yahoo.com

Follow this and additional works at: https://digitalcommons.usf.edu/jometr

Part of the Hospitality Administration and Management Commons, Marketing Commons, and the Tourism and Travel Commons

\section{Recommended Citation}

Elkhwesky, Z., Salem, I. E., \& Barakat, M. (2021). Importance-implementation of disability management practices in hotels: The moderating effect of team orientation. Journal of Mediterranean Tourism Research, 1(1), 22-38. https://www.doi.org/10.5038/2770-7555.1.1.1003

Corresponding Author

Zakaria Elkhwesky, 22756, Shoubrakhet, Beheira, Egypt

Revisions

Submission date: March 10, 2021; 1st Revision: April 17, 2021; Acceptance: July. 29, 2021 


\title{
Importance-Implementation of Disability Management Practices in Hotels: The Moderating Effect of Team Orientation
}

\section{Zakaria Elkhwesky ${ }^{1}$, Islam Elbayoumi Salem², and Mona Barakat ${ }^{3}$}

\author{
Faculty of Tourism and Hotels \\ Alexandria University, Egypt. \\ ${ }^{1}$ zakaria.elkhwesky@alexu.edu.eg \\ ${ }^{3}$ mona_barakat2000@yahoo.com \\ ${ }^{2}$ University of Technology and Applied Sciences, Salalah, Oman. \\ 2 islam.sal@cas.edu.om
}

\begin{abstract}
The purpose of this study is to examine the importance of disability management practices (DMPs) and the level of implementation from the viewpoint of food and beverage ( F \& B) managers, F \& $\mathrm{B}$ entry-level employees, working in F \& B departments, and human resources (HRs) managers in five-star hotels in Egypt. It also analyzed the moderating role of team orientation (TO) between the importance and the implementation of DMPs. Data were collected from 400 respondents. The association between the importance and the implementation of DMPs is significant, moderate, and positive. The results also exhibited that the correlation between the importance and the implementation is significantly more positive under the condition of a high encouragement of TO. The study provides significant implications for both theory and practice.
\end{abstract}

Keywords: disability management practices, importance-implementation analysis, hotels, Egypt.

\section{Introduction}

Diversity among people includes physical appearance, disability, age, religion, education, language, and values (Dastane \& Eshegbe, 2015). Disability is an important diversity category that increases in the workplace (Boehm \& Dwertmann, 2015; Thompson, 2016). Central Agency for Public Mobilization and Statistics (CAPMAS) (2006) documented that the number of handicapped people in the Egyptian society is (475576). Aretz and Hansen (2003) confirmed that diversity management (DM) is essential to manage teams and individuals, and to solve complicated problems in organizations. It is necessary to plan, implement policies, communicate well, use conflict solution skills, and create dialogues to manage diversity in the workplace (Flagg, 2002; Koonce, 2001; Vallaster, 2005; Wambui et al., 2013).

Even though DM is a new trend in HR management, it is not studied well (Elkhwesky et al., 2018, 2019; Subeliani \& Tsogas, 2005). Korjala (2013), Rijamampianina and Carmichael (2005) verified that diversity is not easy to be managed. DM is important for hotels (Korjala, 2013). However, there are few researches directed on studying the importance-implementation of DMPs and analyzing the moderating role of TO in this industry, specifically in Egypt. According to the best of researchers' knowledge, disability management has largely been ignored in Egypt. To fill this 
gap, this study aims at analyzing the importance-implementation of DMPs and examining the moderating effect of TO in five-star hotels, specifically in Cairo and Sharm El-Sheikh cities of Egypt. This research is one of the first researches conducted on workforce diversity in Egypt. The study's problem can be stated in the following question:

- What is the importance-implementation of DMPs and the moderating effect of TO?

\section{Literature Review}

\section{The Concept of Diversity}

Diversity is the differences among individuals in such issues as physical and mental ability, spiritual orientation, and sexual orientation (Esty et al., 1995). Besides, diversity is the differences among people in such terms as sexual orientation, socioeconomic background, and capabilities or disabilities (Jones \& George, 2010). More recently, workforce diversity is defined as similarities and variations among employees regarding age, gender, perspectives, social and psychological characteristics, perceptions, cultural background, physical abilities and disabilities, race, caste and religion, language, qualification, geographic regions, and sexual orientation (Saxena, 2014).

DM refers to the process of managing people by planning and implementing organizational practices and systems (Cox, 1994). According to U.S. Government Accountability Office (2005), DM can be defined as the process of creating and maintaining a positive work environment by taking into consideration similarities and differences among individuals to achieve organizational goals and objectives. In addition, El-Said (2013) and Elkhwesky et al. (2018, 2019) indicated that it is necessary to manage diversity in a proper way among workers to create a suitable workplace in hotels. Without proper management of diversity, a high turnover and conflict will be caused (Boehm \& Dwertmann, 2015).

\section{Diversity Management Practices}

Actions speak louder than words (Iverson, 2000). Formalized practices implemented by firms to manage diversity well refer to diversity management practices (MPs) (Yang \& Konrad 2011a). Besides, Mazur (2015) stated that DM is not just a program, but also an understanding of how to manage the operation and HRs in a supportable way. Starostka-Patyk et al. (2015) assured that DM is a critical part of corporate social responsibility policy. Ultimately, Wrench (2016) stated that $\mathrm{DM}$ is providing minorities an equal employment opportunity.

\section{Disability Management Practices}

People with disabilities may have a physical disability, a sensory, mental, or an intellectual disability. In addition, they have a problem with working and sharing in life (International labour organization, 2002). According to Booth et al. (2009), disabled employees have a physical problem, a mental problem (learning difficulties, such as dyslexia), sensory problem, or newly discovered disabilities (illness or injury) that may prevent them from working in a usual way. International labour organization (ILO) (2002) defined disabilities management as the process of making a workplace suitable for disabled people to work and providing them with all needs. 
Disabled employees should be provided with equal traits (Barak, 2013). An employment of disabled people is necessary to avoid spreading of poverty in the world, reduce costs that are resulted from providing them with benefits, and to improve the national economy (ILO, 2002). Only three percent of disabled people are employed in Kazakhstan and there is a café that employs disabled people with mental problems (Boronilo, 2016). According to Wambui et al. (2013), funding is provided by the Kenyan government to organizations for hiring disabled individuals (physical, mental, or emotional).

In the Egyptian context, the ministry of youth and sports (2014) indicated that there are agreements with the private sector companies, such as restaurants, hotels (the Hyper Group), and food factories for the employment of people with disabilities. In the same vein, the ministry of the manpower and immigration (2016) illustrated that Egypt is proud of disabled persons because they have a strong role in the building of the modern Egypt. Moreover, this ministry helps them work and protects them in the workplace through legislation and regulations. Based on management, organizations can benefit from disability diversity. For clarify, effective management for disability diversity can enhance creativity, commitment, and performance, while poor management could cause a low performance and a high discrimination (Boehm \& Dwertmann, 2015).

It is critical to support employees regularly (Elhoushy \& El-Said, 2020; Salem et al., 2021a). The working environment in Marriott is suitable for individuals with disabilities (Marriott, 2013). Based on ILO (2002), it is essential to support and assist disabled people in the workplace and life. Further, they should be provided with transport and housing as others, the opportunity to return to the job after an absence due to injury or illness, suitable equipment, a proper working time, an easily accessible workplace, equal opportunities in advancement, recruitment, and training, and a safe and healthy workplace. According to Booth et al. (2009), the employer should treat disabled employees in a particular manner. It is vital to avoid a highly restrictive sickness policy, prevent discrimination, and to provide them with proper equipment and premises. After an employment of a person, it is essential to give him/her an awareness training about disabled staff in the workplace.

An individual who has a cancer disease should not be punished because of a long absence in the work. The firm can provide an ill worker with a full pay when leaving it for a period of time from one to six months. More, it is necessary to avoid asking applicants about their sicknesses. The advertisement for the job should not be directed to a specific disability without affording a logical reason. Based on ILO (2002), advertisements of employment should be published in print, on the radio, and on the internet to be available to disabled people. The selection criteria should not prevent them from being employed in the organization. Additionally, it is crucial to provide disabled people with work trails that are important to measure their capabilities and to provide them with valuable work experiences which increase their subsequent employability. As well, information about promotional opportunities should be available for them. Disabled employees should be encouraged to apply for promotion. Training programs need to be appropriate for them and it is required to provide them with visual illustrations, printed materials, and handbooks. Thus, we proposed:

- Hypothesis 1. There is a relationship between the importance and the implementation of DMPs.

- Hypothesis 2. There is a significant variance between the importance and the implementation of DMPs. 


\section{Diversity Management and TO}

Based on Shanahan et al. (2007), TO can be defined as the commitment team members exhibit to working together. Further, it refers to the trust each team member has in the other team members, team pride, and esprit de corps. One of Hilton's values is the teamwork (Hilton Worldwide, 2016b). TO can be defined as the tendency of individuals to work as a part of a team or group to perform tasks (Driskell \& Salas, 1992; O'Shea et al., 2004). It means collaboration of organizational members in carrying out activities and making decisions related to the business (Hult \& Nichols, 1999). Recently, teamwork is to work with others to accomplish a goal (WebFinance, 2017). Teamwork is considered as one of the important concepts for researchers (Hanaysha \& Tahir, 2016). Teams in the workplace are important for firms (Greenberg et al., 2012). More specifically, teamwork is critical in the foodservice operations to achieve better outcomes with fewer resources (Wolf, 1998).

If diversity is managed in a poor way, it will cause conflict and destroy the teamwork and productivity in the organization (Gardenswartz \& Rowe, 2009). Besides, conflict among team members is a challenge facing the success of tasks (Barak, 2013; Elbaz et al., 2020). Goals and objectives cannot be achieved if there is no teamwork among individuals (Saxena, 2014). Bektas and Sohrabifard (2013) revealed that building a teamwork in the firm is vital to increase productivity, profitability, and to develop employees' skills. Team working is beneficial for both employees and managers. To benefit from staff and to achieve a cooperation in the firm, it is critical to provide them with the chance to work in teams. As well, every person in the team should be provided with the chance to achieve his/her targets.

Shanahan et al. (2007) stated that teams are vital to perform complex tasks in the workplace. There are many practices to manage diversity in a proper way. These practices include encouraging the use of a common language among all workers and motivating their participation (Saxena, 2014). Creating a teamwork atmosphere among staff has a profound importance for managing diversity in the workplace (Farren \& Nelson, 1999). More, team working is critical for satisfying employees (Hanaysha \& Tahir, 2016). Employee involvement programs which concern on communication and team working may lead to proper outcomes in a diverse workplace. To create a connection among labors in the organization, it is significant to involve them in a teamwork (Yang \& Konrad, 2011b).

Besides, to manage personnel properly, it is necessary for the top management to respect their viewpoints, encourage the brainstorming, reward good teams, and support and encourage teams to perform the determined tasks (Thamizhmanii \& Hasan, 2010). Furunes and Mykletun (2005) resulted that building teams are critical in the place of work to avoid conflicts. The following hypotheses have been proposed:

- Hypothesis 3. TO moderates the relationship between the importance and the implementation of DMPs. 
Figure 1: Conceptual Framework

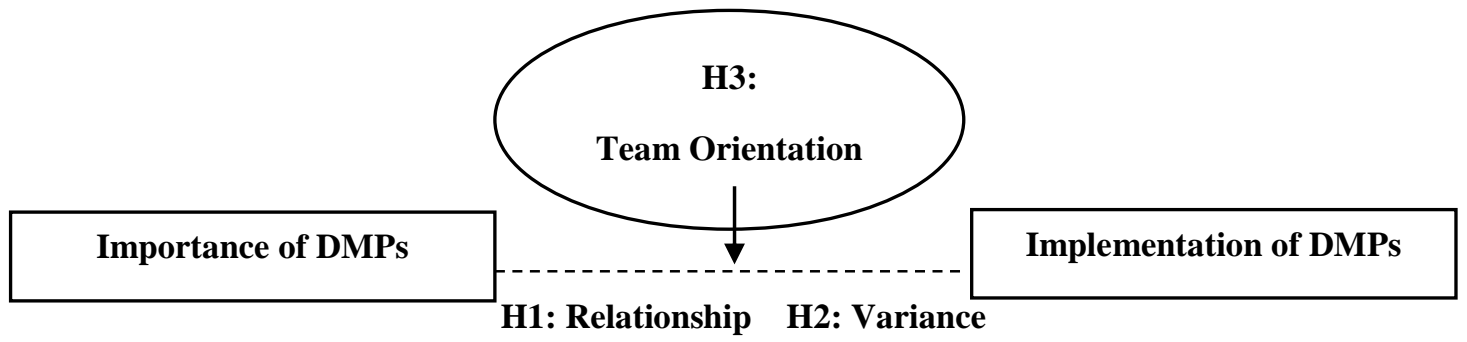

\section{Methods}

\section{Sample and Procedures}

A self-administered questionnaire was used to collect quantitative data. The respondents were $\mathrm{F}$ \& B managers, entry-level F \& B employees, working in F \& B departments, and HR managers in five-star hotels in Cairo and Sharm El-Sheikh of Egypt because they are important tourist destinations in Egypt that have many hotels (Elkhwesky et al., 2018, 2019). Five-star hotels were chosen because they may have diverse employees as a result of their large sizes. Marriott has a diverse workforce (Marriott, 2016). In addition, the general manager of Hilton pyramids golf in Egypt (2015) affirmed that the hotel employs people with disabilities in the kitchen. The F \& B departments were chosen because F \& B management is complex (Rutherford \& O'Fallon, 2007). More, Nebel et al. (1994) affirmed that F \& B management is a challenge in full-service hotels. F \& B managers were chosen because their responsibility for leading, supervising, and motivating employees (Hubsch,1966). They also have more knowledge, experiences, and skills in the fivestar hotels (Nebel et al.,1994). Entry-level employees were selected because this category is important for firms (Hanaysha \& Tahir, 2016). HR managers were surveyed because they are responsible for managing diversity among workers (Gomez-Mejia \& Palich, 1997).

The total number of five-star hotels in Sharm was 42; while Cairo had 29 hotels (Egyptian Hotel Guide, 2015-2016). Based on the complete census technique, hotels were selected. Therefore, 71 five-star hotels were surveyed for data collection. The total number of hotels that were willing to collaborate was 42 hotels with a response rate of 59\% (31 in Sharm and 11 in Cairo). The total number of F \& B managers, entry-level F \& B employees, and HR managers in all accepted fivestar hotels was 3820. The authors selected 45 respondents from each hotel in Cairo and 21 from each hotel in Sharm, totaling 1146 employees and managers.

Measurement items were adapted to fit the current study context. In addition, it was essential to translate the questionnaire into Arabic for administration purpose. It was reviewed and evaluated, for clarity and content, through a convenience sample of ten academic experts in Alexandria University. Subsequently, a pre-test was performed to check face validity and to reduce measurement error. The pilot survey was issued to 16 hotel employees and managers from four hotels before data collection. Based on these results, minor changes were made.

The Cronbach's Alpha $(\alpha)$ for constructs showed acceptable internal consistency. For the importance scale, the $(\alpha)$ coefficient is $(0.9)$; while for the implementation scale, the $(\alpha)$ is $(0.9)$. The $(\alpha)$ coefficient for the TO scale is (0.9) (see table 1). After conducting the pilot study, the survey was distributed personally to F \& B managers, entry-level F \& B employees, and HR 
managers in five-star hotels, during July and August 2017. Out of 1146 questionnaires distributed, only 400 valid questionnaires returned back, with a response rate of $35 \%$ and were used for data analysis.

Table 1: Reliability Analysis

\begin{tabular}{lc}
\hline Construct & Cronbach's Alpha \\
\hline Importance of DMPs & .9 \\
Implementation of DMPs & .9 \\
Team Orientation & .9 \\
\hline
\end{tabular}

\section{Measures}

The questionnaire comprised 28 questions. Participants were asked to illustrate the importance of DMPs on a 5-point Likert-style scale ( $1=$ Unimportant at all, $5=$ Very Important). Also, they were asked to indicate the level of implementation on a 5-point Likert-style scale $(1=$ Absolutely No, $5=$ Absolutely Yes). Items that were used to measure the importance and the implementation of DMPs were adapted from ILO (2002), Booth et al. (2009), Barak (2013), and Wambui et al. (2013).

Participants were requested to illustrate the support of the hotel for TO in F \& B departments; on a 5-point Likert-style scale (where $1=$ Means Strongly Disagree and $5=$ Means Strongly Agree). Items that were used to measure TO were adapted from Denison (2000), Shanahan et al. (2007), and Hanaysha and Tahir (2016). For the study's purpose, TO means the collaboration and cooperation of employees in the workplace in order to achieve a goal. Disabled employees (workers or people) refer to individuals with a physical disability, such as a hearing, visual, or / and speaking impairment and also those with a discovered disability, such as an injury or illness.

In addition, the authors used the open-ended question "Please indicate for us any suggestions or recommendations related to the research topic". This question was important to allow participants to express their perspectives regarding the survey. The answers to the open-ended question were carefully considered and then were used to support the discussion of the quantitative findings (ElSaid \& Aziz, 2021).

\section{Data Analysis and Results}

SPSS version 23.0 was used for data analysis. The PROCESS macro free tool for SPSS from Hayes was used to calculate the moderating effect of TO. Data normality was tested. The $p$-value for all constructs was $=.000$ basing on Kolmogorov-Smirnov ${ }^{\mathrm{a}}$ test and Shapiro-Wilk test, therefore; the data significantly deviated from a normal distribution. Importance-implementation analysis was used to evaluate the importance and the implementation of DMPs.

\section{Respondents'Profile}

As shown in Table 2, the majority of respondents were entry-level F \& B employees (78\%). The vast majority of participants worked in restaurants (39.8\%). Most participants had the Egyptian ethnicity $(93 \%)$. As of educational background, the highest part of participants $(54.3 \%)$ received a bachelor's degree. The majority of respondents were male $(88.8 \%)$. As of religion, the majority were Muslims (82.5\%). Most of the respondents were not married (37.3\%). 
Table 2: Respondents' Profile

\begin{tabular}{|c|c|c|c|}
\hline Question & Category & $n$ & $\%$ \\
\hline \multirow[t]{3}{*}{ Position } & F \& B managers & 65 & 16.3 \\
\hline & HR mangers & 23 & 5.8 \\
\hline & Entry-level F \& B employees & 312 & 78.0 \\
\hline \multirow[t]{12}{*}{ Place of Work } & No Answer & 30 & 7.5 \\
\hline & Restaurant & 159 & 39.8 \\
\hline & Café & 17 & 4.3 \\
\hline & Bar & 43 & 10.8 \\
\hline & Discotheque & 5 & 1.3 \\
\hline & Kitchen & 43 & 10.8 \\
\hline & Room Service & 39 & 9.8 \\
\hline & Banquet & 16 & 4.0 \\
\hline & And Conference Section & & \\
\hline & Human Resources Department & 24 & 6.0 \\
\hline & Staff Cafeteria & 4 & 1.0 \\
\hline & Other & 20 & 5.0 \\
\hline \multirow{5}{*}{ Ethnicity } & Nubian & 4 & 1.0 \\
\hline & Bedouin & 3 & 0.8 \\
\hline & Egyptian & 372 & 93.0 \\
\hline & Foreigner & 7 & 1.8 \\
\hline & Other & 14 & 3.5 \\
\hline \multirow[t]{6}{*}{ Marital Status } & No Answer & 29 & 7.3 \\
\hline & Not Married & 149 & 37.3 \\
\hline & Married & 121 & 30.3 \\
\hline & Married & 100 & 25.0 \\
\hline & with Children & & \\
\hline & Divorced & 1 & 0.3 \\
\hline \multirow[t]{2}{*}{ Gender } & Male & 355 & 88.8 \\
\hline & Female & 45 & 11.3 \\
\hline \multirow[t]{2}{*}{ Religion } & Muslim & 330 & 82.5 \\
\hline & Christian & 70 & 17.5 \\
\hline \multirow[t]{5}{*}{ Age } & No Answer & 29 & 7.3 \\
\hline & Less than 25 years & 101 & 25.3 \\
\hline & 25 and less than 35 years & 151 & 37.8 \\
\hline & 35 and less than 45 years & 86 & 21.5 \\
\hline & 45 years and more & 33 & 8.3 \\
\hline Educational & No Answer & 28 & 7.0 \\
\hline \multirow[t]{8}{*}{ Background } & Student & 6 & 1.5 \\
\hline & Less than secondary school & 11 & 2.8 \\
\hline & Secondary school & 18 & 4.5 \\
\hline & Technical school & 104 & 26.0 \\
\hline & Graduate & 217 & 54.3 \\
\hline & (Bachelor's Degree) & & \\
\hline & Post-graduate & 9 & 2.3 \\
\hline & Other & 7 & 1.8 \\
\hline \multirow[t]{2}{*}{ Job Status } & Contracted Employee & 373 & 93.3 \\
\hline & Casual Employee & 27 & 6.8 \\
\hline
\end{tabular}

Note: $\mathrm{N}=400$

\section{The Relationship between Importance and Implementation of DMPS}

Spearman Correlation (rs) was applied to investigate the correlation between the importance and the implementation of DMPS. Based on table (3), there was a significant and moderate positive correlation between the importance and the implementation of DMPs (rs-value $=0.345, p$-value $=$ $.000<0.01)$. Hence, hypothesis (1) was accepted in the current study. 
Table 3: Spearman's Correlation Coefficient $\left(\mathrm{r}_{\mathrm{s}}\right)$

\begin{tabular}{lcc}
\hline Diversity Dimension & $\begin{array}{c}\text { Spearman's } \\
\text { Correlation }\left(\mathbf{r}_{\mathbf{s}}\right)\end{array}$ & $\boldsymbol{P}$-value \\
\hline Disability (Importance \& Implementation) & $0.354 * *$ & .000 \\
\hline
\end{tabular}

Note: * Correlation is significant at the 0.01 level (2-tailed).

\section{Importance-Implementation Analysis}

Table (4) illustrated the mean importance and the implementation ratings of the 13 items of DMPs. More, it displayed the performance gaps and T-Test statistics. The gap was negative in all cases which meant that the implementation was less than the importance of DMPs. Both the performance gab analysis and T-test statistics indicated that the gaps were non-zero. Additionally, all the performance gaps were significant $(P$-value $=.000<0.05)$. The significant gap for DMPs was $(-$ $0.77, P$-value $=.000<0.05)$. Paired samples T-Tests displayed that there were significant variances between the importance and the implementation mean scores. The findings that were indicated in table (4) accepted hypothesis (2). The next subtitle explained the variations between the importance and the implementation of DMPs.

Table 4: Importance and Implementation Mean Ratings (Mean Difference between ImportanceImplementation of DMPs Attributes).

\begin{tabular}{|c|c|c|c|c|c|}
\hline $\begin{array}{l}\text { Attribute } \\
\text { Number }\end{array}$ & Attribute Description & $\begin{array}{c}\text { Mean } \\
\text { Importance } \\
\text { Rating }\end{array}$ & $\begin{array}{c}\text { Mean } \\
\text { Implementation } \\
\text { Rating }\end{array}$ & $\begin{array}{c}\text { Gap } \\
(\text { P-I })\end{array}$ & $\begin{array}{c}P \text {-value } \\
\text { (Significance) }\end{array}$ \\
\hline & Disability (Overall Mean) & 4.33 & 3.56 & -0.77 & $.000 *$ \\
\hline 1. & $\begin{array}{l}\text { Providing an equal treatment for disabled } \\
\text { employees. }\end{array}$ & 4.40 & 3.77 & -0.63 & $.000^{*}$ \\
\hline 2. & $\begin{array}{l}\text { Hiring a number of disabled individuals in the F } \\
\& \text { B department according to the Egyptian } \\
\text { governmental law }(5 \%) \text {. }\end{array}$ & 4.18 & 3.48 & -0.7 & $.000 *$ \\
\hline 3. & $\begin{array}{l}\text { Providing equal recruitment and advancement } \\
\text { opportunities for disabled employees. }\end{array}$ & 4.22 & 3.49 & -0.73 & $.000 *$ \\
\hline 4. & $\begin{array}{l}\text { Providing a full payment for ill employees during } \\
\text { an ill leave. }\end{array}$ & 4.38 & 3.57 & -0.81 & $.000^{*}$ \\
\hline 5. & $\begin{array}{l}\text { Providing equal and appropriate training } \\
\text { opportunities for disabled employees. } \\
\text { Informing newly disabled employees with job }\end{array}$ & 4.36 & 3.51 & -0.85 & $.000^{*}$ \\
\hline & $\begin{array}{l}\text { instructions and rules, and health and safety } \\
\text { procedures followed in the workplace. }\end{array}$ & 4.42 & 3.66 & -0.76 & $.000 *$ \\
\hline 7. & $\begin{array}{l}\text { Providing a required awareness training about } \\
\text { rights and needs of disabled personnel in the } \\
\text { workplace. }\end{array}$ & 4.36 & 3.57 & -0.79 & $.000 *$ \\
\hline 8. & $\begin{array}{l}\text { Fairness in the performance evaluation of disabled } \\
\text { and non-disabled employees. }\end{array}$ & 4.37 & 3.75 & -0.62 & $.000 *$ \\
\hline 9. & $\begin{array}{l}\text { Providing suitable entrances, toilets, and } \\
\text { washrooms for disabled emplovees. }\end{array}$ & 4.33 & 3.36 & -0.97 & $.000 *$ \\
\hline 10. & $\begin{array}{l}\text { Providing a proper working time for disabled } \\
\text { employees. }\end{array}$ & 4.28 & 3.49 & -0.79 & $.000^{*}$ \\
\hline 11. & $\begin{array}{l}\text { Providing the opportunity to return to the work } \\
\text { after absence due to injury or illness. }\end{array}$ & 4.33 & 3.65 & -0.68 & $.000 *$ \\
\hline 12. & $\begin{array}{l}\text { Providing suitable, safe, and healthy work } \\
\text { environment for disabled employees. }\end{array}$ & 4.40 & 3.73 & -0.67 & $.000 *$ \\
\hline 13. & $\begin{array}{l}\text { Providing fair benefits, such as transport and } \\
\text { housing for disabled employees. }\end{array}$ & 4.21 & 3.32 & -0.89 & $.000^{*}$ \\
\hline
\end{tabular}




\section{Disability}

All the DMPs are very important; except hiring a number of disabled individuals in the F \& B department according to the Egyptian governmental law $(5 \%)(\bar{x}=4.18)$, providing fair benefits, such as transport and housing for disabled employees $(\bar{x}=4.21)$, and providing equal recruitment and advancement opportunities for disabled employees $(\bar{x}=4.22)$. These three practices are important with the least mean importance ratings in comparison with other DMPs.

However, the very important practices with high mean ratings include informing newly disabled employees with job instructions and rules, and health and safety procedures followed in the workplace $(\bar{x}=4.42)$, providing an equal treatment for them $(\bar{x}=4.40)$, and providing them with suitable, safe, and healthy work environment $(\bar{x}=4.40)$. DMPs are mostly implemented, but the slightest implemented MPs with the least mean scores are providing fair benefits, such as transport and housing for disabled employees $(\bar{x}=3.32)$ and providing suitable entrances, toilets, and washrooms for disabled employees $(\bar{x}=3.36)$. The utmost implemented practices with the highest mean ratings include providing an equal treatment for disabled employees $(\bar{x}=3.77)$ and fairness in the performance evaluation of disabled and non-disabled employees $(\bar{x}=3.75)$.

\section{Importance-Implementation Matrix}

The 13 attributes of DMPs were represented on the importance-performance analysis graph. This grid had four quadrants (Figure 2). Most of items fell in quadrants B (keep up the good work) and $\mathrm{C}$ (low priority), but a few of them fell in the quadrant A (concentrate here) and no items fell in the quadrant $D$ (possible overkill). Based on this matrix, practices (Number $=5,9$ ) had a high importance, but they were less implemented. Practices (Number $=2,3,10,13$ ) were low important and less implemented. The most DMPs had a high importance with a high implementation. These practices' numbers were $(1,4,6,7,8,11,12)$. The five-star hotels should concentrate on the quadrant (A) to achieve a high implementation of the high important DMPs. In addition, they should maintain the high implementation of the DMPs fallen in the quadrant (B).

Figure 2: Importance - Implementation Analysis "Grid"

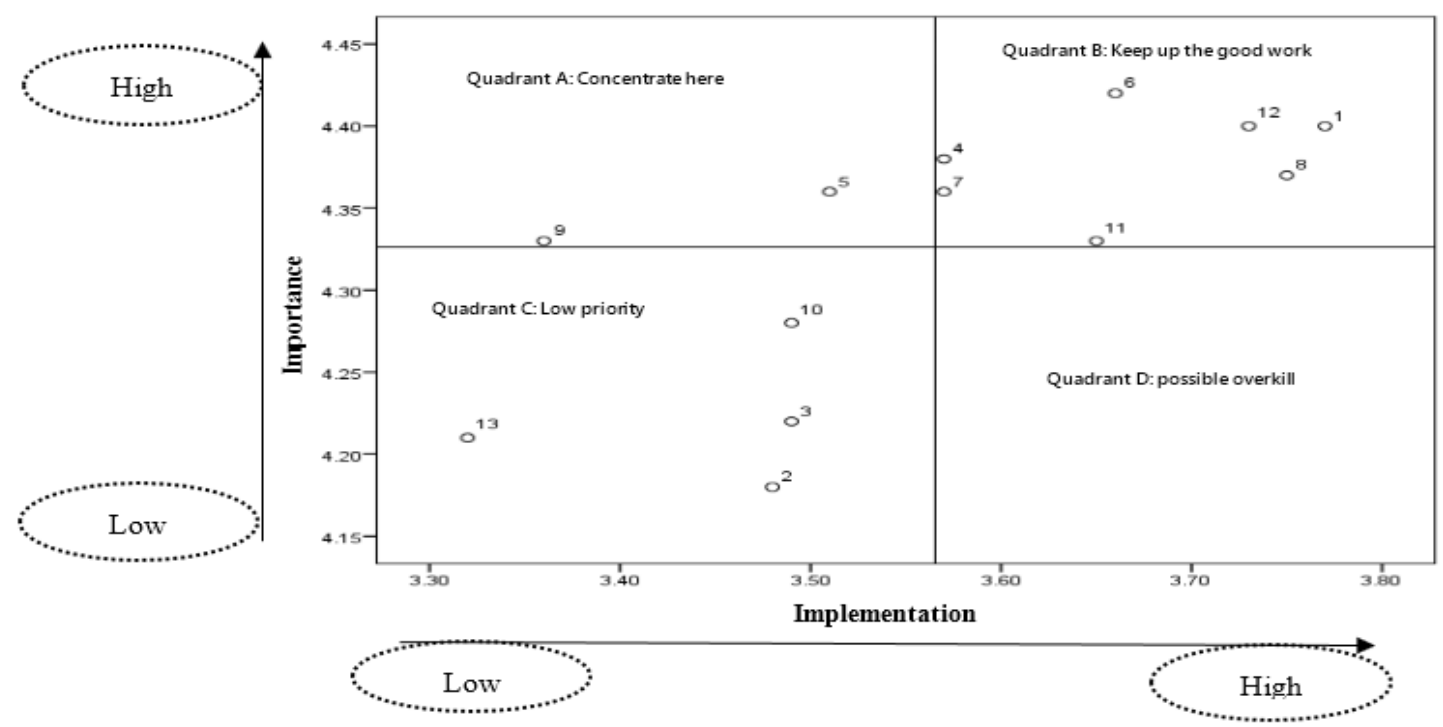




\section{The Variances among Respondents' Positions}

In order to evaluate the variances among F \& B managers, F \& B entry-level employees, and HRs managers regarding DMPs, Kruskal-Wallis $\mathrm{H}$ was applied in this study as a non-parametric test. Our findings revealed that there are significant differences among all positions concerning the implementation of DMPs $(P$-value $=0.001<0.05)$, while there is no difference regarding the importance of DMPs $(P$-value $=0.345>0.05)($ Table 5 $)$.

Table 5: Comparison among F \& B Managers, F \& B Entry-Level Employees, and HRs Managers Regarding the Implementation DMPs.

\begin{tabular}{lccc}
\hline DMPs & $\begin{array}{c}\text { F \& B managers } \\
\text { Mean } \\
\text { Implementation Rating }\end{array}$ & $\begin{array}{c}\text { F \& B entry-level employees } \\
\text { Mean } \\
\text { Implementation Rating }\end{array}$ & $\begin{array}{c}\text { HRs managers } \\
\text { Mean } \\
\text { Implementation Rating }\end{array}$ \\
\hline 1 & 3.57 & 3.79 & 4.04 \\
2 & 3.03 & 3.56 & 3.52 \\
3 & 3.12 & 3.55 & 3.65 \\
4 & 3.46 & 3.55 & 4.13 \\
5 & 3.15 & 3.56 & 3.96 \\
6 & 3.15 & 3.74 & 4.00 \\
7 & 3.20 & 3.62 & 3.91 \\
8 & 3.40 & 3.79 & 4.13 \\
9 & 2.88 & 3.46 & 3.39 \\
10 & 3.02 & 3.60 & 3.35 \\
11 & 3.20 & 3.71 & 4.04 \\
12 & 3.22 & 3.82 & 4.04 \\
13 & 2.62 & 3.44 & 3.70 \\
\hline
\end{tabular}

\section{The Moderating Effect of TO}

The current study resulted that F \& B departments supported and encouraged TO ( $\bar{x}: 4.13)$. Kruskal-Wallis test showed that there were not significant differences among diverse positions $(p$ value $=0.7>0.05)$. A model of a linear regression with a moderating influence was calculated. As shown from table (6), the value of adjusted $\mathrm{R}^{2}$ is (.0532), $\mathrm{F}$ value equal 7.86 and significant at .005 , pointing that $5.32 \%$ of the total variance in the implementation of DMPs is explained by the TO. The findings revealed that TO moderates the association between the importance and the implementation of DMPs.

Based on Johnson-Neyman technique, the correlation between the importance and the implementation of DMPs becomes more positive with the highest TO $(b=.84, t=10.38, p=.0000)$. Results showed that the association between the importance and the implementation of DMPs is significantly more positive under the condition of a high encouragement of TO (See Figure 3). Hence, hypothesis (3) was supported in the current study.

Table 6: Model Summary \& Interaction Effect

\begin{tabular}{|c|c|c|c|c|c|c|c|}
\hline Model Summary & $R$ & $R^{2}$ & MSE & $\mathbf{F}$ & dfI & df2 & $p$ \\
\hline & .5927 & .3513 & .6453 & 91.9286 & 3.0000 & 396.000 & .0000 \\
\hline R-square increase due to interaction(s) & & $R^{2}$-chng & & $\overline{\mathbf{F}}$ & dfI & df2 & $p$ \\
\hline Int - 1 & & .0532 & & 7.8644 & 1.0000 & 396.0000 & .0053 \\
\hline
\end{tabular}


Figure 3: The Moderating Effect of Team Orientation

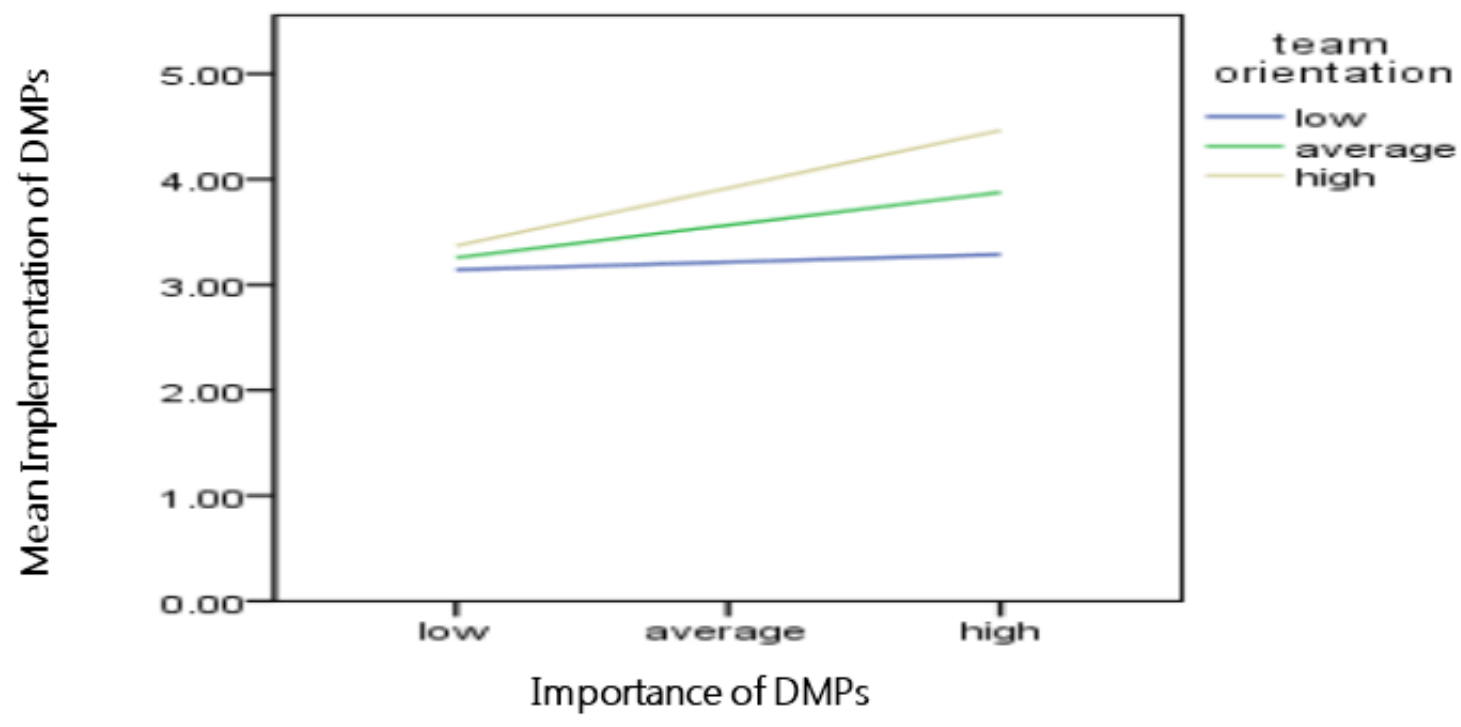

Figure 4: Result of Hypotheses Testing

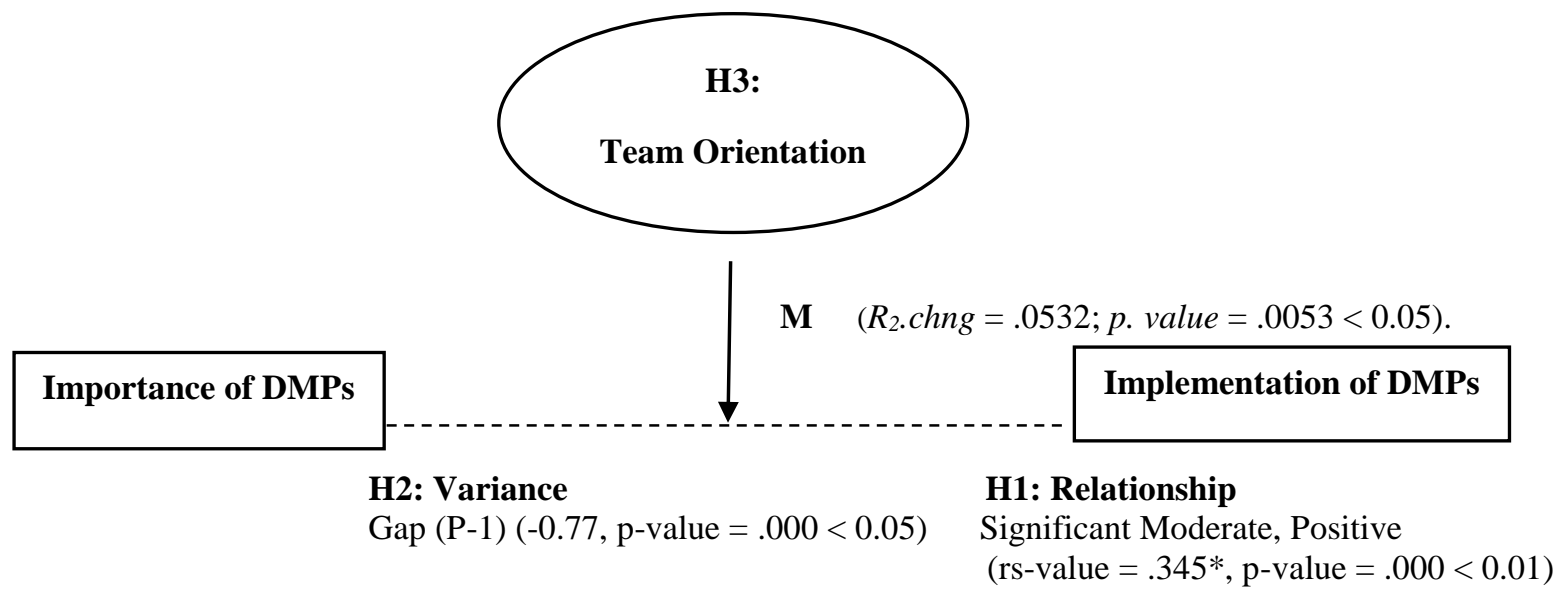

\section{Discussion and Conclusion}

\section{Conclusion}

The objectives of this study were to examine the importance and the implementation of DMPs from the viewpoint of F \& B managers, F \& B entry-level employees, and HRs managers in fivestar hotels. It also analyzed the moderating role of TO between the importance and the implementation of DMPs. 400 questionnaires were used for data analysis. Our findings confirmed that diversity management is a complex process. The F \& B management is responsible for implementing diversity MPs in the F \& B departments through cooperation with the upper management of hotels and the HR departments. Most HR managers indicated that policies of hotels aim at attracting diverse employees, since diversity is very critical to improve organizational performance, create innovation, develop marketing plans, and to achieve a competitive advantage 
in hotels. This goes in line with Allen et al. (2004), Rijamampianina and Carmichael (2005), and Salem et al. (2013).

Our results exhibited that diversity in hotels was found in terms of disability, age, religion, gender, ethnicity, marital status, education, and job status. However, the number of disabled employees is fewer nowadays in hotels. The practice of hiring a number of disabled people in the F \& B departments according to the Egyptian governmental law (5\%) is one of the low important and less implemented practices. Due to the hard nature of working in hotels, very few hotels recruit disabled employees. Moreover, each hotel recruits no more than two disabled employees. As stated by Houtenville and Kalargyrou (2015), the nature of leisure and hospitality businesses does not prevent the recruitment of disabled persons.

Managers affirmed that disabled people are recruited in areas such as staff cafeteria, engineering and maintenance, storage areas, staff housing, security, and housekeeping as order takers clerks, but without dealing directly with guests. Other disabled employees are hired in human resources, kitchen as stewards, purchasing, laundry, and accounting departments. A restaurant manager inside a five-star hotel said that there is a disabled employee with a mentality problem in the steward's position. More, the reason for his recruitment is that there is no employee in this position. Thus, the hotel prefers recruiting someone rapidly and his disability is discovered by the management lately.

Examples of disabilities types inside maintenance and security departments in the five-star hotels include people with a problem in the movement of legs and with a problem in eyes. Some of disabled individuals have a managerial position, such as a manager with a problem in his eyes. Based on our findings, almost HR and F \& B managers refuse recruiting disabled people in guestcontact areas. However, they can be hired in the back area as stewards, and in the staff cafeteria. There are chefs in kitchens with a hearing impairment, but they are prevented from contacting with guests to avoid any problems that may occur. Examples of disabilities in the F \& B departments in non-guest contact areas include people with a hearing, visual and speaking impairment, atrophy in limbs, atrophy in hands, a mentality problem (hard of understanding), heart diseases, and screws in legs.

Most managers encourage recruiting disabled people in non-guest contact areas, because many of them have the motivation to work and produce. Moreover, Gröschl (2007) affirmed that recruiting employees with disabilities is beneficial for hotels to achieve productivity, solve critical problems, and increase return-on-investment. Our results revealed that transportation and staff housing are provided for all employees either disabled or non-disabled in Sharm hotels. This is due to hotels are located in remote areas and to enjoy accommodation and facilitate moving. Managers verified that there is no sufficient financial support from the Egyptian ministry of the manpower to employ disabled workers in hotels. Financial support is very useful to educate, train, make them successful in the society, and to provide them with their needs inside the workplace. This is not consistent with Wambui et al. (2013) who stated that human right activists and the Kenyan government provide organizations with funding to employ disabled workers.

There is no discrimination between disabled and non-disabled employees regarding the number of work hours. Concerning evaluating employees' performance, HR and F \& B departments cooperate with each other to evaluate their performance. Disabled employees are evaluated as others, because 
they are recruited in suitable areas for their disability. According to an assistant HR manager and a recruitment manager, there are two types of a sick leave. Firstly, a sick leave results from an injury during work, with a full payment. Second, a normal sick leave results from an illness, with only $75 \%$ of the total salary of an employee. An employee can take a sick leave with a full payment through medical insurance only. According to F \& B supervisors, there are three types of a sick leave. Firstly, a sick leave results from an injury during work, with a full payment. Second, a sick leave results from a permanent injury needed a long-time period more than one year, with a basic salary only. Third, a sick leave results from an injury outside work; with a full payment. According to an evaluation of the hotel's doctor, the period of the leave is determined.

Results revealed that the association between the importance and the implementation of DMPs is significant, moderate, and positive. In addition, significant variances between the importance and the implementation of DMPs were found. TO was supported and encouraged in hotels. This goes in line with Hilton Worldwide (2016a) which illustrates that building skills and teams is a part of its policy.

The current research concluded that the association between the importance and the implementation of DMPs is significantly more positive under the condition of a high encouragement of TO. It means that supporting TO from the upper management is significant in the implementation of DMPs. This is consistent with Saxena (2014) who sated that encouraging participation of all employees is critical to manage diversity in a proper way. The current study goes in line with Farren and Nelson (1999) who affirmed that creating a teamwork atmosphere among employees is crucial to manage diversity in the workplace well. Teamwork is encouraged within successful operations to help employees work together to support each other towards achieving organizational goals (Ovidiu-Iliuta, 2014). More, encouraging the five-star hotels for the TO in the F \& B departments is critical to create a work environment where the F \& B managerial employees work with the entry-level employees as a team to implement DMPs.

\section{Theoretical Contribution}

Theoretically, this study is perhaps the first in Egypt to focus on examining the importanceimplementation of DMPs and analyzing the moderating role of TO. Different positions participated in this study. It also used a sample of five-star hotels in the Egyptian sector in contrast to most past empirical researches whose data were often exclusively foreign countries. The current study has been carried out to respond to the recent calls from other scholars to assess the importance-implementation of DMPs (Elkhwesky et al., 2018, 2019).

\section{Practical Implications}

DMPs have to be formalized and written in hotels to be followed by all managers. They should be developed and changeable according to the development in work environments. To achieve a success in marketplaces, HR managers should recruit diverse employees. The Egyptian ministry of tourism has to educate and train HR and F \& B managers by concerning the valuable and important practices that should be implemented for managing diversity successfully and concerning how to communicate with diverse workers. Efficiency and dedication to work should be the criteria when hiring an employee in a managerial position. Based on Gröschl (2007), it is recommended for hotels to review and realign employee selection criteria that focused on physical 
attractiveness and aesthetic skills, with guidelines and principles that are ethical and nondiscriminatory.

Criteria should be the same for evaluating employees' performance. Iverson (2000) advised hotel managers to respect diverse employees. Hotels are recommended to maintain the high implementation of the high important DMPs (figure 2). More, F \& B and HR managers are advised to maintain the high implementation of providing suitable, safe, and healthy work environment. It is critical to provide all personnel with job instructions and rules, and health and safety procedures followed in the workplace. Five-star hotels can provide suitable, safe, and healthy work environment for personnel by preventing such risks as noise and vibration, lighting, atmospheric changes, electricity, harmful radiation, and risk of explosion.

This study implies that the ministry of the manpower should monitor all five-star hotels, because some of them do not recruit disabled workers in all departments. There is no sufficient financial support from this ministry to employ disabled employees in hotels according to managers' opinions. However, financial support is critical for hotels to educate disabled employees, train them, and to provide them with their needs inside the workplace. Gröschl (2007) confirmed that governmental financial incentives can motivate hotels hiring persons with disabilities.

Five-star hotels can benefit from hiring disabled employees, because many of them have the desire to work and produce efficiently and effectively. It is advisable to be hired in the F \& B departments in non-guest contact areas or in other departments basing on the type of disability and the nature of work. Hotels are advised to provide appropriate and equal training opportunities for disabled employees. It is recommended for managers to foster stronger communication and relationship building between employees with and without disabilities, through pushing for policies and work environments (Gröschl, 2007). Barak (2013) affirmed that equal traits should be provided for workers with disabilities. Justice or fairness is important for employees' job satisfaction and organizational commitment (Salem et al., 2021b).

To strengthen the positive association between the importance and the implementation of DMPs, upper management in hotels should encourage and support TO regularly. To manage diversity and create successful teamwork, hotel managers should provide all employees and managers in hotels with ongoing training about how to contact with different cultures in the workplace.

The implementation of diversity MPs will be succeeded as a result of the spirit of collaboration between employees and managers. Upper management of hotels, HR managers, and F \& B managers should cooperate to operate diversity among employees in $\mathrm{F} \& \mathrm{~B}$ departments effectively. Upper management in hotels should give high-qualified and experienced managers in all departments, the opportunity of making creative changes in HR management in the workplace according to the organizational culture of the chain or hotel. Hotel managers need to create dialogues with F \& B and HR managers about managing for diversity. Upper management in hotels should establish organizational culture that encourages the recruitment of diverse employees and motivates TO which is very critical in diversity management.

Less classified-hotels can benchmark the high important and implemented DMPs to make the success in their marketplaces and workplaces. HR managers are advised to contact faculties and institutions of tourism and hotels to recruit a number of qualified personnel in F \& B departments 
who will be able to share creative ideas that will be useful for managerial employees. Institutions and faculties of tourism and hotels have to provide students with educational curriculums for diversity MPs to have knowledge that will be useful in the future when working in hotels.

\section{Limitations and Future Research}

This study was adopted a positivist research philosophy. It is recommended for future scholars to use mixed-method designs to exhibit the management practices used to manage personnel with diverse educational backgrounds, ethnicities, religion, gender, and ages. This research was conducted in the Egyptian hotels. Hence, our model and propositions should be tested and validated in different contexts globally. Making comparisons among different hotels' departments is essential because this study focused on F \& B departments.

\section{References}

Allen, R., Dawson, G., Wheatley, K., \& White, C. S. (2004). Diversity practices: Learning responses for modern organizations. Development and Learning in Organizations. An International Journal, 18(6), 13-15.

Aretz, H. J., \& Hansen, K. (2003). Successful management of diversity. The multicultural organization as a strategy to improve sustainable competitiveness. Journal of Personnel Research / German Journal of Research in Human Resource Management, 17(1), 9-36.

Barak, M. E. M. (2013). Managing diversity: Toward a globally inclusive workplace. Sage.

Bektas, C., \& Sohrabifard, N. (2013). Terms of organizational psychology, personnel empowerment and team working: A case study. Procedia-Social \& Behavioral Sciences, 82, 886-891.

Boehm, S. A., \& Dwertmann, D. J. (2015). Forging a single-edged sword: Facilitating positive age and disability diversity effects in the workplace through leadership, positive climates, and HR practices. Work, Aging and Retirement, 1(1), 41-63.

Booth, N., Robson, C., Welham, J., Barnard, A., \& Bartlett, N. (2009). Tolley's managing a diverse workforce. Routledge.

Boronilo, D. (2016). Kazakhstan cafe kicks stigma with mentally disabled staff. Mysinchew. http://www.mysinchew.com/node/115265/tid=13.

Central Agency for Public Mobilization and Statistics (CAPMAS) (2006). Statistical book. Capmas. www.capmas.gov.eg

Cox, T. (1994). Cultural diversity in organizations: Theory, research and practice. Berrett-Koehler.

Dastane, O., \& Eshegbe, G. W. (2015). Diversity elements in the workplace: A study on diversity factors at workplace in hotels at Klang valley Malaysia. International Journal of Accounting, Business and Management, 1(1), $260-283$.

Denison, D. R. (2000). Organizational culture (OC): Can it be a key lever for driving organizational change. In S. Cartwright \& C. Cooper (Eds.), The handbook of organizational culture (OC) and climate (347-376). Wiley.

Driskell, J. E., \& Salas, E. (1992). Collective behavior and team performance. Human Factors, 34(3), $277-288$.

Egyptian Hotel Guide (34th edition) (EHG, 2015-2016).

Elbaz, A. M., Salem, I., Elsetouhi, A., \& Abdelhamied, H. H. (2020). The moderating role of leisure participation in workleisure conflict for the reduction of burnout in hotels and travel agencies. International Journal of Tourism Research, 22(3), 375-389.

Elkhwesky, Z., Salem, I. E., \& Barakat, M. (2018). Age diversity management in five-star hotels: Importanceimplementation analysis. Journal of Tourism Research, 20, 74-88.

Elkhwesky, Z., Salem, I. E., \& Barakat, M. (2019). Diversity management in hotels: The moderating role of empowerment and capability development. Journal of Hospitality and Tourism Insights, 2(2),166-185.

El-Said, O. A. (2013). Effects of creativity support and diversity management on employees' perception of service quality in hotels. Journal of Human Resources in Hospitality \& Tourism, 12(3), 291-312.

Elhoushy, S., \& El-Said, O. A. (2020). Hotel managers' intentions towards female hiring: An application to the theory of planned behaviour. Tourism Management Perspectives, 36, 2-12. 
El-Said, O., \& Aziz, H. (2021). Virtual tours a means to an end: An analysis of virtual tours' role in tourism recovery post COVID-19. Journal of Travel Research, 1-21. https://doi.org/10.1177/0047287521997567

Esty, K. C., Griffin, R., \& Hirsch, M. S. (1995). Workplace diversity. Adams media corporation.

Farren, C., \& Nelson, B. (1999). Retaining diversity do all you can to retain the diversity you hire. Executive Excellence, $16,7-7$.

Flagg, A. (2002). Managing diverse workgroups successfully. United Behavioral Health.

Furunes, T., \& Mykletun, R. J. (2005). Age management in Norwegian hospitality businesses. Scandinavian Journal of Hospitality and Tourism, 5(2), 116-134.

Gardenswarzt, L., \& Rowe, A. (2009). The effective management of cultural diversity’. In M. Moodian (Eds.), Contemporary leadership and intercultural competence: Exploring the cross-cultural dynamics within organizations. Sage.

Gomez-Mejia, L. R., \& Palich, L. E. (1997). Cultural diversity and the performance of multinational firms. Journal of International Business Studies, 28(2), 309-335.

Greenberg, E. S., Sikora, P. B., Grunberg, L., \& Moore, S. (2012). Work teams and organizational commitment: exploring the influence of the team experience on employee attitudes. Citeseerx. http://citeseerx.ist.psu.edu/viewdoc/download?doi=10.1.1.331.7453\&rep=rep1\&type=pdf.

Gröschl, S. (2007). An exploration of HR policies and practices affecting the integration of persons with disabilities in the hotel industry in major Canadian tourism destinations. International Journal of Hospitality Management, 26(3), 666-686.

Hanaysha, J., \& Tahir, P. R. (2016). Examining the effects of employee empowerment, teamwork, and employee training on job satisfaction. Procedia-Social and Behavioral Sciences, 219, 272-282.

Hilton Worldwide (2016a, 29 December). Hiltonworldwide. http://www.hiltonworldwide.com/about/mission/

Hilton Worldwide (2016b, 29 December). Team members' factsheet. Hiltonworldwide. Hiltonworldwide.cr.hiltonworldwide.com/download/Hilton_CRReport_Team_Members.pdf .

Houtenville, A., \& Kalargyrou, V. (2015). Employers' perspectives about employing people with disabilities: A comparative study across industries. Cornell Hospitality Quarterly, 56(2), 168-179.

Hubsch, A. W. (1966). Hotel food and beverage management. Cornell Hotel and Restaurant Administration Quarterly, 7(3), 9-11.

Hult, G.T.M., \& Nichols Jr, E. L. (1999). A study of team orientation in global purchasing. Journal of Business \& Industrial Marketing, 14(3), 194-212.

International Labour Organization (ILO) (2002). Managing disability in the workplace: ILO code of practice. Ilo. http://www.ilo.org/skills/pubs/WCMS_103324/lang--en/index.htm.

Iverson, K. (2000). Managing for effective workforce diversity: Identifying issues that are of concern to employees. The Cornell Hotel and Restaurant Administration Quarterly, 41(2), 31-38.

Jones, G. R., \& George, J. M. (2010). Essentials of contemporary management. McGraw-Hill Ryerson.

Koonce, R. (2001). Redefining diversity. Training Development, 55(12), 22-33.

Korjala, V. (2013). Cultural diversity in hospitality management: How to improve cultural diversity workforce [Bachelor's Thesis]. Thesus. http://www.theseus.fi/handle/10024/55331.

Marriott (2013). Business conduct guide. Marriott. https://www.marriott.com.au/Multimedia/PDF/CorporateResponsibility/Marriott_Business_Conduct_Guide_Englis h.pdf.

Marriott (2016, 29 December). Marriott. https://www.marriott.com.au/diversity/diversity-and-inclusion.mi.

Mazur, B. (2015). Sustainable human resource management. The attempt of holistic approach. Economics and Management, 7(2), 7-12.

Nebel, E. C., Braunlich, C. G., \& Zhang, Y. (1994). Career paths in American luxury hotels: Hotel food and beverage directors. International Journal of Contemporary Hospitality Management, 6(6), 3-9.

O'Shea, P. G., Driskell, J. E., Goodwin, G. F., Zbylut, M. L., \& Weiss, S. M. (2004). Development of a conditional reasoning measure of team orientation. Apps. https://apps.dtic.mil/sti/pdfs/ADA427947.pdf 
Ovidiu-Iliuta, D. (2014). The link between organizational culture and performance management practices: A Case of it companies from Romania. The annals of the University of Oradea, Economic Science Series, 23, 1156-1163.

Rijamampianina, R., \& Carmichael, T. (2005). General issues in management: A pragmatic and holistic approach to managing diversity. Problems and Perspectives in Management, 3(1), 109-117.

Rutherford, D. G., \& O'Fallon, M. J. (2007). Hotel management and operations. Ndl.ethernet.

Ndl.ethernet.http://ndl.ethernet.edu.et/bitstream/123456789/78903/7/Hotel_Management\%20\%20and\%20Operation s.pdf.

Salem, I. E. B., El-Said, O. A., \& Nabil, M. (2013). Determinants and effects of applying electronic Marketing in Alexandria Hotels: Current status and future trends. Journal of Tourism and Hospitality, 2(2), 112.

Salem, I. E., Elbaz, A. M., Elkhwesky, Z., \& Ghazi, K. M. (2021a). The COVID-19 pandemic: The mitigating role of government and hotel support of hotel employees in Egypt. Tourism Management, 85. https://doi.org/10.1016/j.tourman.2021.104305.

Salem, I. E., Elkhwesky, Z., \& Ramkissoon, H. (2021b). A content analysis for government's and hotels' response to COVID-19 pandemic in Egypt. Tourism and Hospitality Research, 1-34. https://doi.org/10.1177/14673584211002614

Saxena, A. (2014). Workforce diversity: A key to improve productivity. Procedia Economics and Finance, $11,76-85$.

Shanahan, C., Best, C., Finch, M., \& Sutton, C. (2007). Measurement of the behavioural, cognitive, and motivational factors underlying team performance (No. DSTO-RR-0328). Australia: Air operations division, defence science and technology organization. Apps. https://apps.dtic.mil/sti/pdfs/ADA476917.pdf

Starostka-Patyk, M., Tomski, P., \& Zawada, M. (2015). Diversity management as a part of corporate social responsibility policy. Procedia Computer Science, 65, 1038-1045.

Subeliani, D., \& Tsogas, G. (2005). Managing diversity in the Netherlands: A case study of Rabobank. The International Journal of Human Resource Management, 16(5), 831-851.

Thamizhmanii, S., \& Hasan, S. (2010). A review on an employee empowerment in TQM practice. Journal of Achievements in Materials and Manufacturing Engineering, 39(2), 204-210.

The general manager of Hilton pyramids golf in Egypt (2015). Dotmsr. http://www.dotmsr.com.

The ministry of manpower and immigration (2016). Manpower. http://www.manpower.gov.eg/specialneeds_persons.html

The ministry of youth and sports (2014). Egynews. http://www.egynews.net/99440

Thompson, N. (2016). Anti-discriminatory practice: Equality, diversity and social justice. Palgrave Macmillan.

U.S. Government Accountability Office (2005). Diversity management: Expert-identified leading practices and agency examples. Gao.Gov. http://www.gao.gov/new. items/d0590.pdf

Vallaster, C. (2005). Cultural diversity and its impact on social interactive processes implications from an empirical study. International Journal of Cross Cultural Management, 5(2), 139-163.

Wambui, T. W., Wangombe, J. G., Muthura, M. W., Kamau, A. W., \& Jackson, S. M. (2013). Managing workplace diversity: A Kenyan perspective. International Journal of Business and Social Science, 4(16), 201-218.

WebFinance Inc. (2017). Business dictionary. http://www.businessdictionary.com/definition/teamwork.html.

Wolf, K. N. (1998). Assessing teamwork skills of foodservice directors and subordinates. Journal of the American Dietetic Association, 98(9), https://doi.org/10.1016/S0002-8223(98)00351-4

Wrench, J. (2016). Diversity management and discrimination: Immigrants and ethnic minorities in the EU. Routledge.

Yang, Y., \& Konrad, A. M. (2011a). Understanding diversity management practices: Implications of institutional theory and resource-based theory. Group \& Organization Management, 36(1), 6-38.

Yang, Y., \& Konrad, A. M. (2011b). Diversity and organizational innovation: The role of employee involvement. Journal of Organizational Behavior, 32(8), 1062-1083. 